\title{
Monitoramento da qualidade da água de cinco rios do litoral da Paraíba: coliformes fecais
}

\author{
Hellen Alves Carneiro, Karoline de Sousa Oliveira, Luis Gustavo \\ Almeida Simplício de Brito, Samara Galvão da Silva, José Marcelino \\ de Lima Silva, João Carlos de Miranda e Silva*
}

Superintendência de Administração do Meio Ambiente (SUDEMA). Coordenadoria de Medições Ambientais. Av. Monsenhor Walfredo Leal, 181. Tambiá, João Pessoa-PB (CEP 58020-540).*E-mail: jota13@gmail.com.

Resumo. As águas que banham os rios urbanos compõem bacias hidrográficas que alimentam todos os ecossistemas são responsáveis pela manutenção da vida marinha, terrestre e essenciais a vida humana. O Brasil é um país banhado por grandes corpos hídricos que abastecem suas comunidades. Contudo, grande parte desses rios apresenta condições depressivas de qualidade de água, fazendo com que seus usos se restrinjam basicamente para navegação e usos secundários. Tendo em vista a importância dos corpos hídricos, o estudo tem como objetivo apresentar o monitoramento da qualidade da água de cinco rios do litoral paraibano, correlacionando o parâmetro medido 'temperatura' com a presença ou ausência e crescimento de microrganismos (coliformes termotolerantes) nesses corpos d'água. Os coliformes termotolerantes são capazes de se desenvolver e fermentar a lactose com produção de acido e gás a temperatura de $44-45^{\circ} \mathrm{C}$, em 24 h. Este grupo de microrganismos é usado como indicativo de contaminação sanitária pelo fato de estarem associados às fezes de animais de sangue quente. Através da análise desses dados, concluímos que o aumento da quantidade de coliformes termotolerantes nos rios amostrados, mesmo que esteja diretamente relacionado ao aumento da temperatura, não tem sido unicamente ocasionado por esses relativos aumentos. Ao invés disso, outros fatores como a grande quantidade de resíduos orgânicos depositados nestes corpos hídricos, através de esgotos, podem ser os responsáveis por esse ‘boom' populacional de bactérias.

Palavras-chave: Coliformes termotolerantes, Contaminação, Rios.

Abstract. Water quality monitoring of five rivers of the coast of Paraiba: fecal coliforms. The waters that bathe the urban rivers make up watersheds that feed all ecosystems are responsible for maintaining marine life, land and essential to human life. Brazil is a country bathed in large water bodies that supply their communities. However, much of these rivers has depressed conditions of water quality, causing its uses are restricted basically to navigation and secondary uses. Considering the importance of water bodies, the study aims to present the monitoring of water quality of five rivers of Paraíba coast, correlating the measured parameter 'temperature' to the presence or absence and growth of microorganisms (fecal coliform) in

Recebido: 10/12/2015

Aceito: 28/12/2015

Publicado: 31/12/2015

Acesso Aberto

Artigo completo

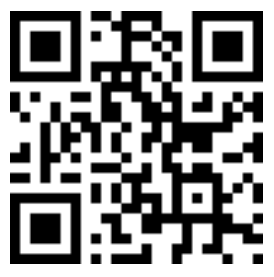


these bodies of water. The coliforms fecal are able to grow and ferment lactose with gas production and acid at a temperature of 44$45^{\circ} \mathrm{C}$ for $24 \mathrm{~h}$. This group of microorganisms is used as indicative of health contamination because they are associated with the feces of warm-blooded animals. By analyzing these data, we conclude that the increased amount of fecal coliforms in sampled rivers, even if it is directly related to the temperature increase has not been solely caused by these relative increases. Instead, other factors such as the large amount of organic waste deposited in these water bodies through sewage, may be responsible for this boom population of bacteria.

Keywords: Thermotolerant coliforms, Contamination, Rivers.

\section{Introdução}

As águas que banham os rios urbanos compõem bacias hidrográficas que alimentam todos os ecossistemas. São responsáveis pela manutenção da vida marinha, terrestre e são essenciais à vida humana. O Brasil é um país banhado por grandes corpos hídricos que abastecem suas comunidades. Contudo, atualmente, boa parte desses rios apresenta condições depressivas de qualidade de água, fazendo com que seus usos se restrinjam basicamente para navegação e usos secundários.

A poluição das águas por material fecal de origem humana e animal torna esse ecossistema veículo de transmissão de doenças infecciosas causadas por bactérias, vírus, protozoários e helmintos, dentre outros. Devido ao seu elevado potencial de disseminação, essas doenças representam um importante risco à saúde humana, e são responsáveis por elevada morbidade e mortalidade, principalmente entre crianças dos países em desenvolvimento (World Health Organization, 2004), como o Brasil.

A detecção de microrganismos patogênicos, embora necessária em algumas circunstâncias, não é aplicável para fins de monitoramento ou verificação de rotina. Por esse motivo, uma das estratégiasmais viáveis para o controle da qualidade microbiológica da água é a avaliação da presença dos chamados microrganismos indicadores de contaminação fecal. Esses microrganismos devem possuir uma série de características, dentre elas, estarem presente em grande quantidade em fezes humanas e de outros animais de sangue quente, não se multiplicar em águas naturais e ser detectável por métodos laboratoriais simples e rápidos (CETESB, 2007).

Segundo a Resolução CONAMA ${ }^{\circ}$ 274/2000 (Brasil, 2000), as águas serão consideradas impróprias quando no trecho avaliado, for verificada uma das seguintes ocorrências:

- Não atendimento aos critérios estabelecidos para as águas próprias; e

- Valor obtido na última amostragem for superior a 2500 coliformes fecais (termotolerantes).

Os usos das águas são estabelecidos e preponderados por comitês, secretarias e agências regulamentadoras que criam planos para o gerenciamento dos corpos hídricos.

Diante do exposto, o presente trabalho visa apresentar o monitoramento da qualidade da água, de rios urbanos da grande João Pessoa, correlacionando os parâmetros temperatura e coliformes termotolerantes.

Este artigo tem como objetivo, apresentar o monitoramento da qualidade da água de alguns rios da Paraíba, correlacionando $\mathrm{o}$ parâmetro medido 'temperatura' com a presença ou ausência e crescimento de microrganismos (coliformes termotolerantes) nesses corpos d'água. 


\section{Material e métodos}

\section{Caracterizações da área de estudo \\ Os rios urbanos de João Pessoa que} foram objeto de estudo deste trabalho são:

Rio Gramame: A Bacia Hidrográfica do Rio Gramame localiza-se entre as latitudes $7^{\circ} 11^{\prime}$ e $7^{\circ} 23^{\prime} \mathrm{S}$ e as longitudes $34^{\circ} 48^{\prime}$ e $35^{\circ} 10^{\prime} \mathrm{W}$, no litoral sul do Estado da Paraíba, e drena uma área de 589,1 $\mathrm{km}^{2}$. Os principais rios que compõem a bacia hidrográfica (Gramame, Mumbaba e Mamuaba), têm as suas nascentes localizadas na proximidade do complexo cristalino na porção sudoeste da bacia (Paz, 1988; Watanabe et al., 1990; Silva et al., 2002).

Rio Abiaí: A Bacia Hidrográfica do Rio Abiaí está inserida entre as latitudes $7^{\circ} 10^{\prime}$ e $7^{\circ} 30^{\prime} \mathrm{S}$ e entre as longitudes $34^{\circ} 48^{\prime}$ e $35^{\circ} 06^{\prime} \mathrm{W}$, a maior parte da qual banha o litoral paraibano, abrangendo uma área de $449,5 \mathrm{~km}^{2}$, e o curso principal em si, o Rio Abiaí, apresenta 28,2 km e extensão.

Rio Guaju: O Rio Guaju nasce no Tabuleiro dos Marcos, Município Potiguar de Canguaretama, a uma altitude aproximada de $87 \mathrm{~m}$ e segue o curso oesteleste até a foz, no Oceano Atlântico. A bacia abrange uma área de $152,6 \mathrm{~km}^{2}$, o que representa apenas $0,27 \%$ da área total do Estado da Paraíba e cerca de $0,30 \%$ do território potiguar.

Rio Graú (ou Rio Garaú): encontra-se localizado no litoral sul da Paraíba, na Praia de Tambaba, dentro da Área de Proteção Ambiental de Tambaba, que possui a maior cobertura de Mata Atlântica da região.

Rio Guruji: Localizado no Município de Conde, a Bacia Hidrográfica do Rio Guruji possui uma área total de $44,70 \mathrm{~km}^{2}$. É composta pelos Riachos Estiva, Caboblo e Pau Ferro, e demais córregos secundários, ainda sem denominações.

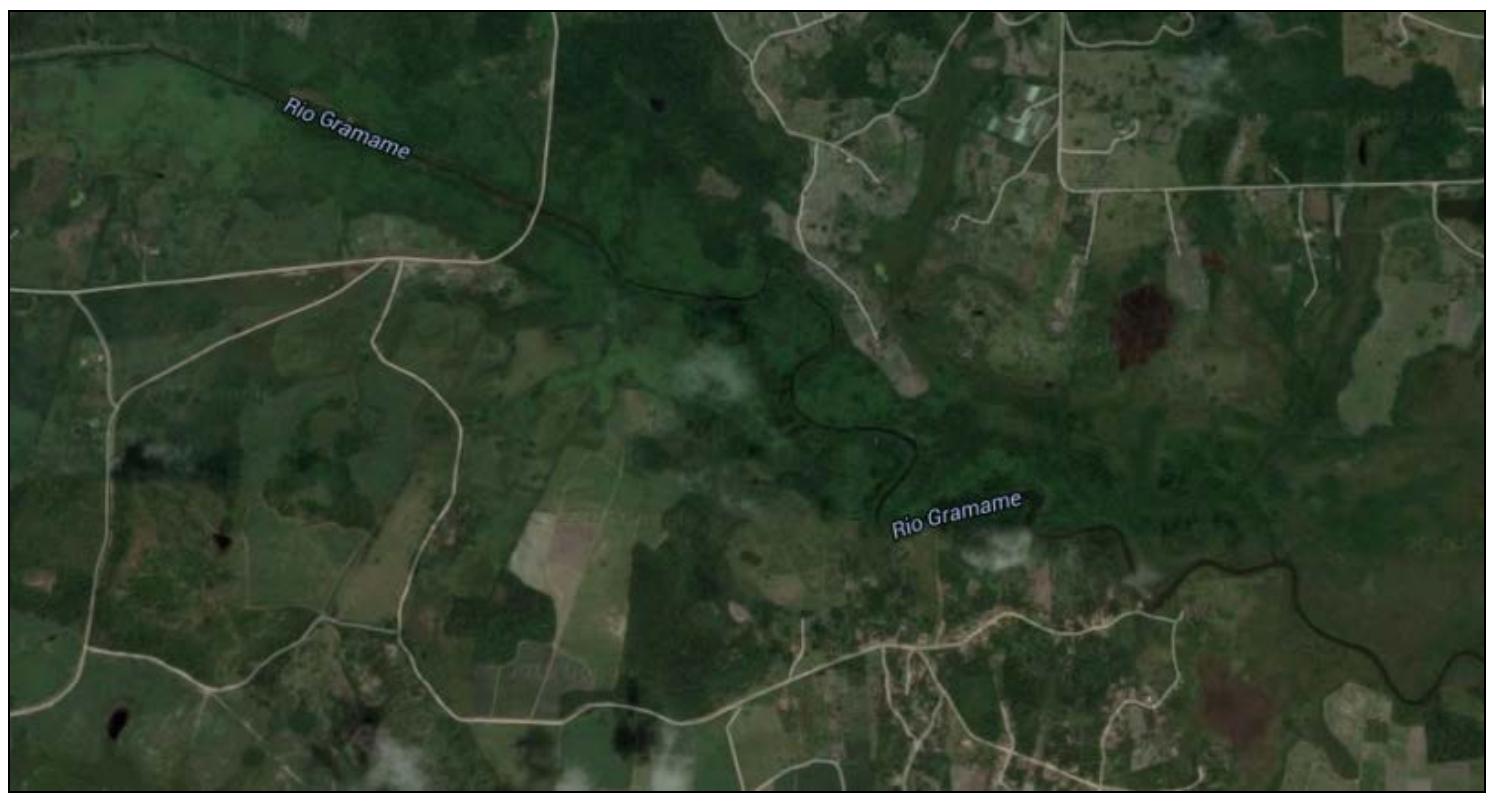

Figura 1. Localização geográfica do Rio Gramame. Fonte: Google Earth. 


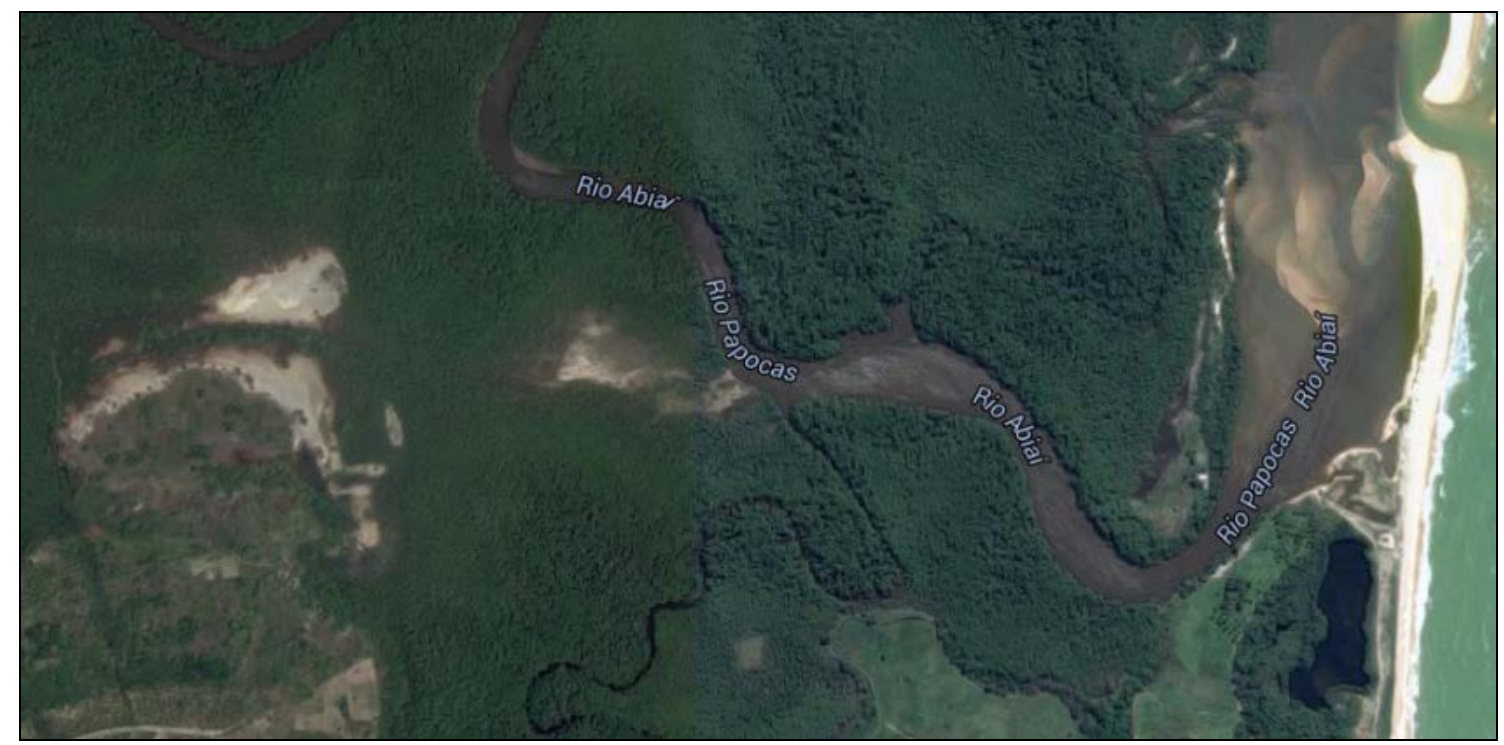

Figura 2. Localização geográfica do Rio Abiaí. Fonte: Google Earth..

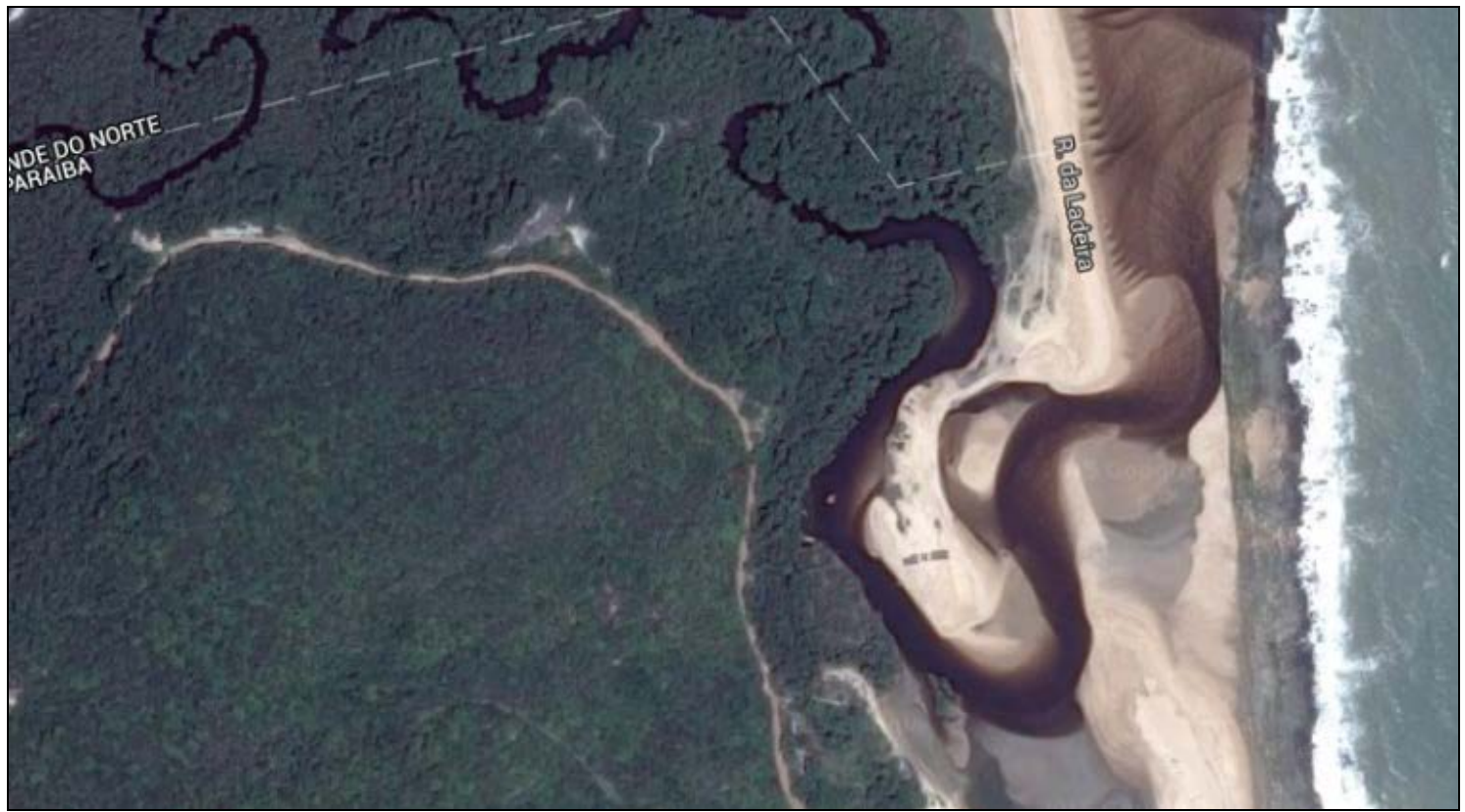

Figura 3. Localização geográfica do Rio Guaju. Fonte: Google Earth.

Rev. Bras. Gest. Amb. Sustent., 2015, v. 2, n. 3, p.121-127. 


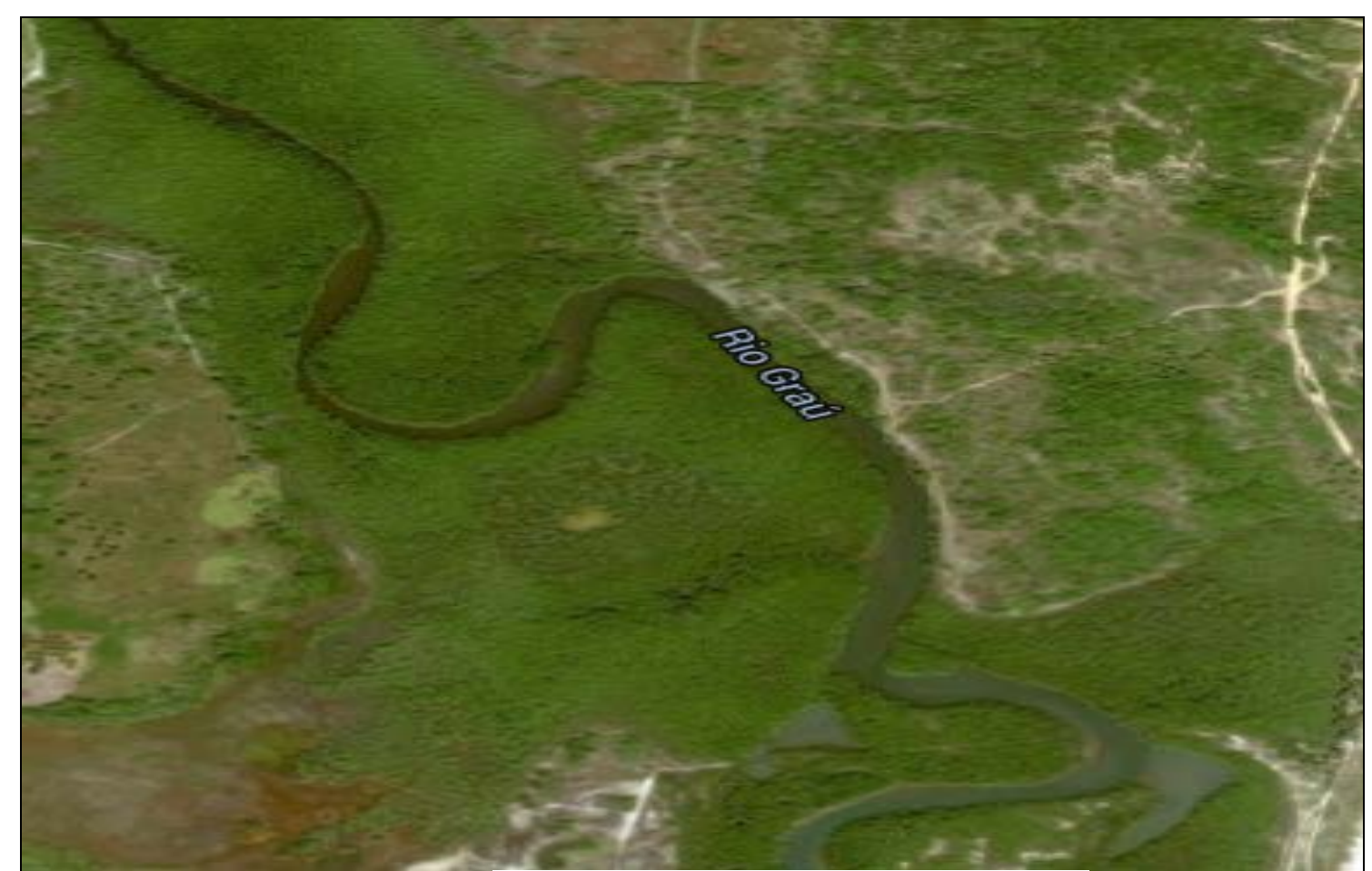

Figura 4. Localização geográfica do Rio Graú (ou Rio Garaú). Fonte: Google Earth.

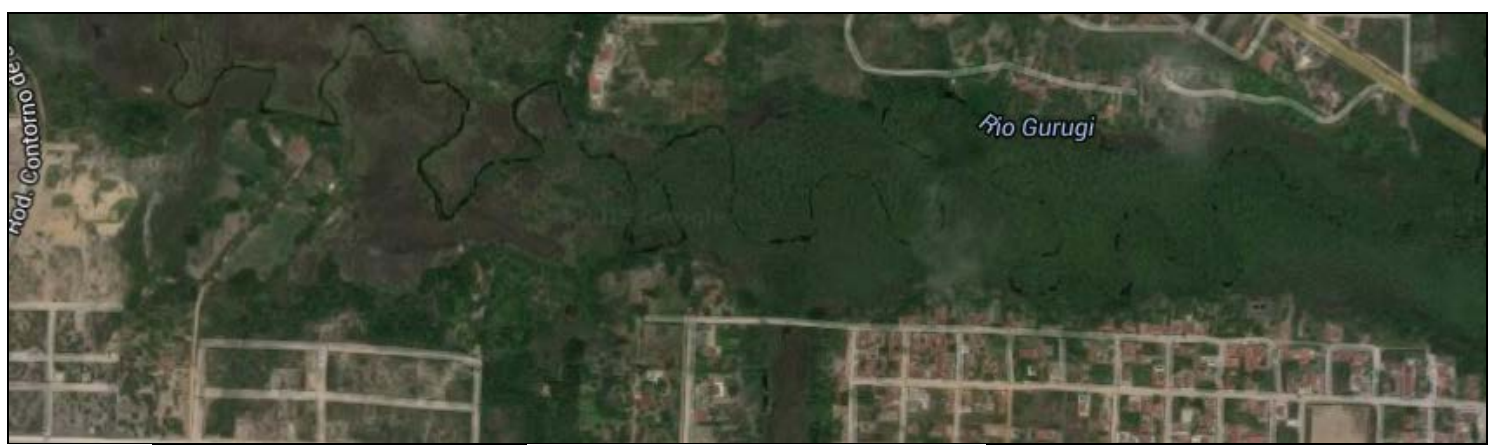

Figura 5. Localização geográfica do Rio Guruji. Fonte: Google Earth.

\section{Etapas metodológicas}

Para a realização do estudo, foram coletadas amostras de cinco rios paraibanos. Após as coletas, as amostras foram mantidas em recipientes hermeticamente fechados e refrigerados para que não houvesseproliferação dos microrganismos antes das análises. Em seguida as amostras foram levadas para análise na Coordenadoria de Medições Ambientais, da Superintendência de Administração do Meio Ambiente (SUDEMA), localizada no Município de João Pessoa, Estado da Paraíba.
Para análise, foram levados em consideração as seguintes variáveis: temperatura e coliformes termotolerantes. A temperatura da amostra foi medida durante a coleta, através de um termômetro. Já os coliformes termotolerantes foram determinados por meio da técnica de membrana filtrante, segundo a metodologia descrita na Norma Técnica CETESB $n^{\circ}$ L5.214/2007 (CETESB, 2007), que quantifica o número de coliformes termotolerantes encontrados nas amostras. Os coliformes termotolerantes são os coliformes capazes de se desenvolver e 
fermentar a lactose com produção de ácido e gás à temperatura de $44-45^{\circ} \mathrm{C}$, em $24 \mathrm{~h}$.

\section{Resultados e discussão}

Os coliformes são um grupo de bactérias indicadoras de contaminação sanitária. Estas bactérias se reproduzem no intestino de animais de sangue quente e são utilizadas como parâmetros para análise da qualidade das águas. Dentro desses grupos de bactérias, estão aquelas que toleram temperaturas acima de $40^{\circ} \mathrm{C}$, chamadas termotolerantes.

Para este caso, a quantidade de coliformes termotolerantes tendeu a aumentar. Isto se deve não exclusivamente à correlação da temperatura com o crescimento das colônias destes organismos, mas principalmente pela elevada deposição de matéria orgânica nos rios.

Na Tabela 1, observa-se certa constância nos valores médios das temperaturas amostradas. As variações aferidas, não explicam por si só o fato do aumento excessivo da quantidade de coliformes encontradas ao longo dos anos.

A Tabela 2 apresenta os dados representativos das quantidades amostradas de coliformes encontrados. Mostrando uma tendência ao aumento ao longo dos anos, porém este aumento não ocorre exclusivamente devido ao aumento da temperatura.

Tabela 1. Valores de temperatura encontrados ao longo dos anos.

\begin{tabular}{|c|c|c|c|c|c|c|c|c|c|c|c|c|c|c|}
\hline & Ab01 & Ab02 & Ab03 & Gr01 & Gr03 & Gr04 & Gr05 & Gr06 & Gr07 & Gu01 & Gj01 & Gj02 & Gj03 & Gi01 \\
\hline 2006 & 27 & 27 & 27 & 27 & 28 & 28 & 28 & 28 & 28 & 28 & 26 & 27 & 28 & 28 \\
\hline 2007 & 26 & 28 & 28 & 26 & 27 & 28 & 28 & 28 & 28 & 28 & 26 & 28 & 28 & 27 \\
\hline 2008 & 26 & 27 & 27 & 26 & 27 & 28 & 28 & 28 & 28 & 27 & 26 & 27 & 28 & 31 \\
\hline 2009 & 26 & 27 & 27 & 26 & 27 & 28 & 28 & 28 & 28 & 27 & 26 & 27 & 28 & 27 \\
\hline 2010 & 26 & 28 & 28 & 27 & 28 & 28 & 28 & 28 & 28 & 28 & 27 & 28 & 28 & 28 \\
\hline 2011 & 27 & 27 & 27 & - & - & - & - & - & - & 27 & 27 & 27 & 27 & 27 \\
\hline 2012 & 30 & 30 & 30 & 27 & 29 & 29 & 29 & 29 & 28 & 30 & 27 & 27 & 27 & 30 \\
\hline 2013 & 27 & 27 & 27 & 27 & 28 & 30 & 29 & 29 & 29 & 27 & 28 & 28 & 28 & 27 \\
\hline 2014 & 27 & 28 & 28 & 28 & 28 & 28 & 27 & 28 & 27 & 28 & 27 & 27 & 27 & 28 \\
\hline
\end{tabular}

Legenda: Ab - Rio Abiaí; Gi - Rio Gurugi; Gj - Rio Guaju; Gr - Rio Gramame; Gu - Rio Grau.

Tabela 2. Quantidade media de colônias de coliformes termotolerantes encontrados nas amostras.

\begin{tabular}{c|cccccccccccccc}
\hline & Ab01 & Ab02 & Ab03 & Gr01 & Gr03 & Gr04 & Gr05 & Gr06 & Gr07 & Gu01 & Gj01 & Gj02 & Gj03 & Gi01 \\
\hline 2006 & 164 & 241 & 265 & 413 & 845 & 942 & 1024 & 242 & 309 & 100 & 85 & 155 & 195 & 1275 \\
2007 & 160 & 253 & 223 & 2690 & 1515 & 1214 & 924 & 374 & 173 & 1471 & 194 & 153 & 328 & 552 \\
2008 & 220 & 212 & 178 & 476 & 1170 & 305 & 366 & 1058 & 987 & 264 & 89 & 125 & 157 & 551 \\
2009 & 136 & 345 & 332 & 516 & 383 & 592 & 2507 & 161 & 34 & 173 & 127 & 159 & 159 & 472 \\
2010 & 136 & 313 & 199 & 1324 & 1747 & 756 & 715 & 76 & 116 & 109 & 236 & 483 & 176 & 280 \\
2011 & 92 & 98 & 163 & - & - & - & - & - & - & 123 & 27 & 51 & 212 & 306 \\
2012 & 310 & 640 & 250 & 2285 & 27605 & 605 & 6055 & 4645 & 2660 & 0 & 53 & 66 & 92 & 1450 \\
2013 & 328 & 587 & 547 & 580 & 900 & 755 & 562 & 205 & 192 & 870 & 272 & 240 & 233 & 2362 \\
2014 & 300 & 463 & 416 & 180 & 1490 & 353 & 210 & 303 & 56 & 135 & 278 & 277 & 390 & 1210 \\
\hline
\end{tabular}

Legenda: Ab - Rio Abiaí; Gi - Rio Gurugi; Gj - Rio Guaju; Gr - Rio Gramame; Gu - Rio Grau.

Para o Rio Gramame, os resultados obtidos para a variável temperatura neste estudo foram similares àqueles encontrados por Paz (1988) e Watanabe et al. (1990), que constataram que as águas desse rio são termicamente homogêneas ao longo de todo o seu percurso e não apresenta flutuações acentuadas entre os diferentes meses. A amplitude de variação térmica máxima anual da água do Rio Gramame encontrada por Paz (1988) foi de $4,0^{\circ} \mathrm{C}$ e Watanabe et al. (1990) encontraram a variação anual da temperatura de $4,5^{\circ} \mathrm{C}$. 
Esses resultados corroboram a hipótese desse estudo de que a temperatura per si não está condicionando a presença de coliformes fecais nesses rio estudados.

\section{Conclusão}

Através da análise desses dados, concluímos que o aumento da quantidade de coliformes termotolerantes nos rios amostrados, mesmo que esteja diretamente relacionado ao aumento da temperatura, não tem sido unicamente ocasionado por esses relativos aumentos. Ao invés disso, outros fatores como a grande quantidade de resíduos orgânicos depositados nestes corpos hídricos, através de esgotos, podem ser os responsáveis por esse 'boom' populacional de bactérias.

\section{Declaração de conflito de interesses}

Os autores declaram não haver conflitos de interesses.

\section{Referências}

Brasil. Leis, decretos, etc. Resolução CONAMA $n^{\circ}$ 274, de 29 de novembro de 2000. Dispõe sobre balneabilidade em águas brasileiras. DOU de 25 de janeiro de 2001.

CETESB. Norma Técnica $\mathbf{n}^{\circ} \mathbf{L} 5.214$, de 30 de agosto de 2007. Coliformes totais determinação pela técnica de membrana filtrante. Disponível em: $<$ http://www.cetesb.sp.gov.br/wp-content/ uploads/sites/11/2013/11/DD_203_DO.pdf>. Acesso em: 21 set. 2015.
Eaton, A. D.; Clesceri, L. S.; Rice, E. W.; Greenberg, A. E.; Franson, M. A. H. (Ed.). Standard methods for the examination of water and wastewater. 21. ed. Washington, D.C.: American Public Health Association, 2005.

Paz, R. J. Estudo das condições físicoquímicas do Rio Gramame, Conde, Paraíba, Brasil. João Pessoa: Universidade Federal da Paraíba, 1988. (Monografia de Graduação). Disponível em: <http://www.ronilsonpaz.net/download/pdf/paz1988.pdf >. Acesso em: 21 set. 2015.

Silva, T. C.; Passerat de Silans, A.; Pedrosa Filho, L. A.; Paiva, A. E. D. B.; Billib, M.; Boochs, P. Planejamento dos recursos hídricos na Bacia Hidrográfica do Rio Gramame, uma bacia litorânea do nordeste brasileiro. Revista Brasileira de Recursos Hídricos, n. 4, p. 121134, 2002. Disponível em: <https://www.abrh.org.br/sgcv3/UserFiles/ Sumarios/3e0d7dbbd001a2b1573f8a9101ad297 9_2f9a45d5932a52ea71cd1fb07b40e6d4.pdf>. Acesso em: 21 set. 2015.

Watanabe, T.; Lima, M. A. M., Machado, V. M. M.; Paz, R. J. Caracterização limnológica do Rio Gramame, João Pessoa (PB), Brasil: variáveis ambientais. Acta Limnologica Brasiliensia, v. 3, n. 1, p. 363-389, 1990. Disponível em: <http://www.ablimno.org.br/ acta/pdf/acta_limnologica_contents301E_files/ Art.14 Vol 3(1).pdf>. Acesso em: 21 set. 2015. 
Informação da Licença: Este é um artigo Open Access distribuído sob os termos da Licença Creative Commons Attribution, que permite uso irrestrito, distribuição e reprodução em qualquer meio, desde que a obra original seja devidamente citada.

Rev. Bras. Gest. Amb. Sustent., 2015, v. 2, n. 3, p.121-127. 